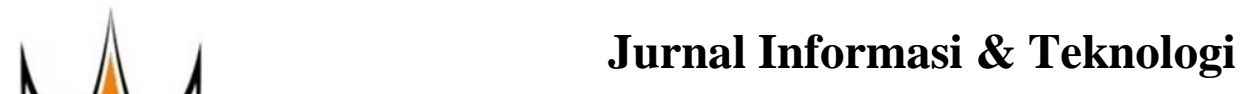

http://www.jidt.org

2020 Vol. 2 No. $1 \quad$ Hal:1-6

e-ISSN: 2714-9730

\title{
Metode Simple Multi Attribute Rating Technique Dalam Keputusan Pemilihan Dosen Berprestasi yang Tepat
}

\author{
Rezi Elsya Putra ${ }^{1}$, Selvia Djasmayena ${ }^{2 \bowtie}$ \\ ${ }^{1}$ Sekolah Tinggi Ilmu Komputer Muhammadiyah Batam \\ ${ }^{2}$ STMIK Citra Mandiri Padang Sidimpuan \\ djasmayenaselvia@gmail.com
}

\begin{abstract}
Each lecturer is required to carry out the tridarma of higher education, a career to become a lecturer must be professional in accordance with his knowledge and expertise. Almost every year state or private tertiary institutions, give an award to lecturers who excel one of the benchmarks is from the tri darma performance of higher education. At present in determining the right lecturer with good achievements there are still many weaknesses of one of the criteria used. Then the research has the aim to determine the outstanding lecturers by using the right criteria effectively. The method used is the Simple Multi Attribute Rating Technique (SMART) method using Sekolah Tinggi Ilmu Komputer (STIKOM) Muhammadiyah Batam's lecturer data. The results of this study set the right criteria, so get a very high level of accuracy which is $79 \%$. So this research becomes the right indicator in determining the outstanding lecturers.
\end{abstract}

Keywords: Simple Multi Attribute Rating Technique (SMART), Lecturer, Achievers, Higher Education, Decision Support System (DSS).

\begin{abstract}
Abstrak
Setiap dosen wajib melaksanakan tridarma perguruan tinggi, berkarir menjadi dosen harus profesional sesuai dengan keilmuan dan keahliannya. Hampir setiap tahun perguruan tinggi negeri atau perguruan tinggi swasta, memberikan suatu penghargaan kepada dosen yang berprestasi salah satu tolak ukurnya adalah dari kinerja tridarma perguruan tinggi. Saat ini dalam menentukan dosen berprestasi yang tepat masih banyak kelemahan salah satu dari ktiteria yang digunakan. Maka penelitian memiliki tujuan untuk menentukan dosen berprestasi dengan menggunakan kriteria yang tepat secara efektif. Metode yang digunakan adalah metode Simple Multi Attribute Rating Technique (SMART) menggunakan data dosen Sekolah Tinggi Ilmu Komputer (STIKOM) Muhammadiyah Batam. Hasil penelitian ini menetapkan kriteria yang tepat, sehingga mendapatkan tingkat akurasi sangat tinggi yaitu 79\%. Maka penelitian ini menjadi indikator yang tepat dalam menentukan dosen berprestasi.
\end{abstract}

Kata Kunci: Simple Multi Attribute Rating Technique (SMART), Dosen, Berprestasi, Pendidikan Tinggi, Sistem Pendukung Keputusan (SPK).

\section{Pendahuluan}

Dosen merupakan salah satu unsur yang terlibat dalam penyelenggaraan pendidikan tinggi. Dosen harus menjadi pendidik yang profesional dalam keilmuan dan pendidikan, penelitian, dan pengabdian kepada telah melaksanakan kegiatan dalam meningkatkan mutu masyarakat di perguruan tinggi negeri maupun swasta tridharma perguruan tinggi [2][3]. Dalam [1]. Berdasarkan UU RI No. 14 tahun 2005 tentang pelaksanaannya, pemilihan dosen berprestasi telah Guru dan Dosen, Pasal 51 Ayat (1) Butir b, bahwa diterapkan setiap tahunnya di Sekolah Tinggi Ilmu Komputer (STIKOM) Muhammadiyah Batam. 
Proses pemilihan dosen berprestasi yang sejumlah kriteria yang memiliki nilai-nilai dan setiap dilaksanakan selama ini di STIKOM Muhammadiyah kriteria memiliki bobot yang menggambarkan seberapa Batam (SMB) dilakukan dengan cara penilaian penting dibandingkan dengan kriteria lain. Pembobotan menggunakan tolak ukur keaktifan saja belum ini digunakan untuk menilai setiap alternatif agar menggunakan tolak ukur yang berkaitan dengan diperoleh alternatif terbaik. tridarma peguruan tinggi yang di lakukan, hasil keaktifan diambil berdasarkan vouting yang terbanyak voting dilakukan oleh para dosen.

Vouting yang terbanyak berhak menjadi dosen berprestasi. Tentunya hasil yang di dapatkan tidak objektif, karena dilakukan hanya pendapat dari dosen tidak tidak didasarkan dengan yang ditentukan dengan tepat, sehingga hasil yang didaptkan terjadinya kecemburuan sosial diantara dosen [4].

Solusi pemecahan permasalahan yang terjadi makan digunakan sebuah cabang ilmu komputer yaitu Sistem Pendukung Keputusan (SPK). SPK merupakan salah bidang ilmu komputer dalam membantu seorang pimpinan untuk menghasilkan keputusan yang spesisik dan penyelesainnya secara spesifik juga [5][6].

Setiap keputusan yang diambil sangat dibutuhkan dalam menentukan keberadaan suatu organisasi. Pengolahan data informasi sangat perlu dilakukan sehingga menghasilkan alternatif keputusan yang dapat diambil keputusan oleh pimpinan. SPK sebagai berbasis komputer terdiri atas tiga komponen yang saling berineteraksi, yaitu sistem bahasa, sistem pengetahuan, dan sistem pemprosesan masalah (hubungan antara dua komponen lainnya [7].

Dalam menentukan keputusan ada beberpa jenis masalah yang dapat digunakan sebagai berikut:

a. Masalah terstruktur : pada masalah terstruktur menggunakan hanya 3 tahapan keputusan (Pemahaman, Perancangan, Pemilihan).

b. Masalah tidak terstruktur : pada masalah ini tidak menggunakan 4 tahapan dari tahapan keputusan.

c. Masalah semi terstruktur: merupakan masalah yang ada diantara terstruktur dan tidak terstruktur, bearti masalah yang dihadapi merupakan tidak dapat memecahkan masalah yang ada.

SPK ini dapat membantu dalam menentukan keputusan dengan menggunakan salah satu metodenya yaitu Simple Multi Attribute Rating Technique (SMART). Metode SMART dapat melakukan pengambilan keputusan dengan multi atribut. Metode pembobotan SMART merupakan metode pendukung keputusan yang paling sederhana, hal ini sesuai dengan pernyataan [8][9].

Metode SMART merupakan sebuah teknik yang digunakan dalam pengambilan keputusan dengan multi kriteria, pada teori bahwa setiap alternatif terdiri dari
Menurut Goodwin dan Wright ada beberapa langkah untuk menganalisa metode SMART seperti beritku ini [10]:

a. Menentukan kriteri untuk setiap alternatif.

b. Menentukan bobot setiap keriteria dengan menggunakan interval 1-100 untuk masing-masing kriteria dengan prioritas terpenting.

c. Hitung Normalisasi Setiap Bobot Kriteria, ada proses ini setiap bobot pada masing-masing kriteria dengan membandingkan nilai bobot kriteria dengan jumlah bobot kriteria, menggunakan rumus berikut ini:

$$
N b=\frac{B k}{\sum B k}
$$

Dimana:

$\mathrm{Nb}$ merupakan normalisasi bobot, $B k$ merupakan bobot dari masing-masing kriteria, $\sum B k$ merupakan total jumlah bobot setiap kriteria.

d. Memberikan data ke kriteria setiap alternatif. Data yang di inputkan ke kriteria untuk setiap alternatif ini dapat berbentuk dua macam data yaitu

1. Data kuantitatif merupakan data berbentuk angka yang sudah bisa diolah langusung tanpa dikonversi lagi.

2. Data kualitatif merupakan data nilai untuk kriteria yang sudah dapat dipastikan berbentuk kuantitatif sedangkan nilai untuk kriteria fasilitas bisa jadi berbentuk kualitatif seperti sangat baik, baik, cukup, kurang cukup, sangat tidak cukup. Apabila nilai kriteria berbentuk data contoh seperti tersebut maka kita perlu mengubah ke data kuantitatif (angka) dengan membuat parameter nilai kriteria, misalkan sangat baik artinya 5 , baik artinya 4 , cukup artinya 3 , kurang cukup artinya 2 , sangat tidak cukup artinya 1.

e. Menentukan nilai utility dengan mengonversikan nilai kriteria pada setiap kriteria, pada metode SMART utility memiliki sifat dapat dilihat pada kepentingan kriteria tersebut seperti berikut ini:

1. Kriteria yang bersifat "lebih diinginkan nilai yang lebih kecil" kriteria seperti (misalkan kriteria penghasilan untuk bantuan keluarga tidak mampu, kriteria bentuk rumah untuk pemberian bantuan keluarga tidak mampu dan lainnya) menggunakan rumus berikut ini: 


$$
U k=100 * \frac{K \max -K i}{K \max -K \min }
$$

2. Kriteria yang bersifat "lebih diinginkan nilai yang lebih besar" kriteria seperti (misalkan jabatan fungsional pada pemilihan dosen terbaik, banyak jumlah jurnal yang di publish oleh dosen dan lainnya) maka untuk itu menggunakan rumus berikut ini:

$$
U k=100 * \frac{K i-K \min }{K \max -K \min }
$$

Dimana:

Uk merupakan utility setiap Kriteri, Ki merupakan nilai Kriteri ke 1 dan seterusnya, Kmin merupakan nilai kriteria terendah dari kriteria ke 1 dan seterusnya dan Kmax merupakan nilai kriteria tetinggi dari kriteria ke 1 dan seterusnya.

f. Menentukan nilai akhir analisa metode SMART dengan mengalikan nilai yang didapat dari normalisasi nilai bobot kriteria dari data data baku dengan nilai normalisasi kriteria dari data baku. Kemudian jumlahkan nilai dari perkalian menggunakan rumus berikut ini:

$$
N t a=\sum_{\mathrm{a}=1}^{\mathrm{n}} B k \cdot U k
$$

Nta merupakan nilai total alternatif, $B k$ merupakan hasil dari normalisasi bobot dan $U k$ merupakan hasil dari normalisasi kriteria.

\section{Metodologi Penelitian}

Agar terarahnya penelitian dengan baik maka diperlukannya keangka penelitian.Kerangka penelitian ini diperlukan untuk mendapatkan metodologi penelitian yang terarah dan memudahkan ketika melakukan analisa terhadap permasalahan dan data yang ada. Berikut ini merupakan kerangka penelitian dari tahapan penelitian seperti yang terlihat pada Gambar 1 dibawah ini:.

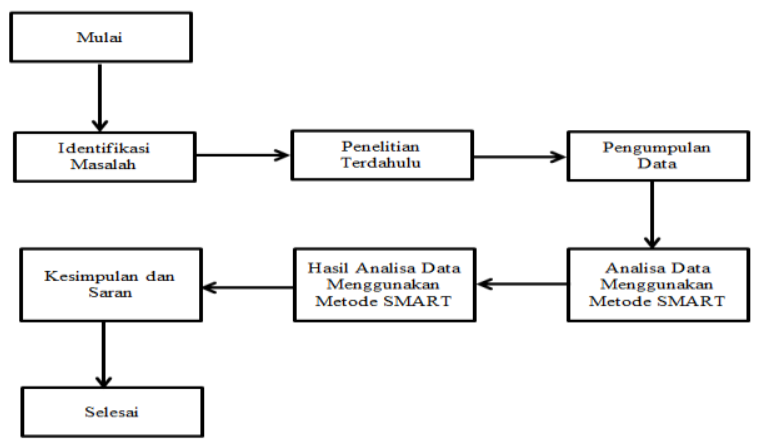

a. Pengumpulan data

Pengumpulan data merupakan hal yang paling penting untuk keberhasilan dari penelitian. Hasil ini sangat berkaitan dengan data yang didapatkan dari sumbernya. Dalam penelitian ini menggunakan dua metode pengumpulan data yaitu:

1. Data Primer

Data primer merupakan salah satu teknik pengumpulan data dengan mengamati langsung ke sumber tempat pengumpulan data dengan teknik:

a. Observasi

Oberservasi ini dilakukan di kampus SMB yang dilaksanakan pada tanggal 11 Januari 2020 - 21 Januari 2020.

b. Wawancara

Pengumpulan data dengan melakukan wawancara dengan bagian akademik SMB, untuk mengumpulkan informasi mengenai data calon dosen berpretasi yang tidak dapat dari teknik observasi.

2. Data Sekunder

Pengumpulan data dengan metode sekunder dimana data yang diperoleh melalui buku-buku referensi, dokumentasi, literature, jurnal, yang berhubungan dengan penelitian pemilihan dosen berprestasi dengan metode SMART.

b. Analisa Data

Dalam menganalisa menggunakan metode SMART ada beberpa langkah yang digunakan yaitu:

1. Menentukan kriteria

Pada penelitian ini peneliti menggunakan 4 kriteria untuk menentukan dosen berprestasi dapat dilihat pada Tabel 1.

Tabel 1. Data Kriteria

\begin{tabular}{ccc}
\hline No & Kriteria & $\begin{array}{c}\text { Inisial } \\
\text { Kriteria }\end{array}$ \\
\hline 1 & Umpan balik mahasiswa & $\mathrm{K} 1$ \\
2 & Jumlah kegiatan pkm 5 tahun terakhir & $\mathrm{K} 2$ \\
3 & Jumlah hibah Penelitia dan PKM 5 & $\mathrm{K} 3$ \\
4 & tahun terakhir & $\mathrm{K} 4$ \\
\hline
\end{tabular}

Sumber: Hasil Penelitian (2020)

Pada Tabel 1 pada kolom Inisial Kriteria menggunakan singkatan dimana $\mathrm{K}$ adalah Kriteria dan nomor 1,2,3,4 merupakan urutan dari setiap kriteria yang ada.

Gambar. Kerangka Penelitian 
2. Menenentukan bobot

Menentukan bobot kritteria dapat dilihat pada Tabel 2 seperti berikut ini:

Tabel 2. Data Bobot

\begin{tabular}{ccc}
\hline No & Kriteria & Bobot \\
\hline 1 & K1 & 1 \\
2 & K2 & 2 \\
3 & K3 & 3 \\
4 & K4 & 4 \\
\hline
\end{tabular}

Sumber: Hasil Penelitian (2020)

Pada Tabel 2 untuk bobot masing-masing kriteriaditetapkan oleh peneliti dan sumber berdasarkan urutan nomor setiap kriteria yang mengacu kepada Tabel 1.

c. Hasil akhir dari Metode SMART adalah mendapatkan hasilnilai yang tertinggi dari analisa data baku dari masing-masing alternatif, sehingga nilai dari masing-masing alternatif tersebut dapat di rangkingkan.

\section{Hasil dan Pembahasan}

Pada tahap ini merupakan perhitungan manual dari metode SMART dengan menggunakan beberapa contoh data calon dosen berprestasi yang ada di kampus SMB:

a. Menentukan Data Alternatif

Data yang digunakan untuk mencari dosen terbaik menggunakan data dari kampus SMB, terdapat data yang diolah berbentuk data kuantitatif dapat dilihat pada Tabel 3 .

Tabel 3. Data Dosen

\begin{tabular}{cccccc}
\hline No & Alternatif & K1 & K2 & K3 & K4 \\
\hline 1 & MI & 29 & 4 & 5 & 8 \\
2 & AZ & 31 & 5 & 4 & 4 \\
3 & LO & 28 & 2 & 0 & 0 \\
4 & ABD & 29 & 2 & 3 & 4 \\
5 & YH & 34 & 4 & 1 & 4 \\
6 & DA & 32 & 3 & 1 & 3 \\
7 & HS & 34 & 2 & 2 & 2 \\
8 & AB & 31 & 3 & 1 & 1 \\
9 & MA & 28 & 4 & 1 & 1 \\
\hline
\end{tabular}

Sumber: Hasil Penelitian (2020) b. Menghitung Normalisasi Bobot

Pada proses ini bobot masing-masing kriteria yang terdapat pada Tabel 2 di analisa dengan rumus persamaan(1) dapat dilihat perhitungannya pada Tabel 4 berikut ini:

Tabel 4. Normalisasi Bobbot

\begin{tabular}{cccc}
\hline No & Kriteria & $\begin{array}{c}\text { Bobot } \\
(\boldsymbol{B} \boldsymbol{k})\end{array}$ & $\begin{array}{c}\text { Perhitungan } \\
(\boldsymbol{N} \boldsymbol{b})=\mathbf{B k} / \sum \boldsymbol{B} \boldsymbol{k}\end{array}$ \\
\hline 1 & $\mathrm{~K} 1$ & 1 & $1 / 10=0.1$ \\
2 & $\mathrm{~K} 2$ & 2 & $2 / 10=0.2$ \\
3 & $\mathrm{~K} 3$ & 3 & $3 / 10=0.3$ \\
4 & K4 & 4 & $4 / 10=0.4$ \\
& $\sum B k$ & 10 & \\
\hline
\end{tabular}

Sumber: Hasil Penelitian (2020)

c. Menentukan sifat utilty tergantung pada kriteria yang diinginkan tingkat kepentingan yang tinggi dan rendah. Pada Tabel 1, semua kriteria yang ada menggunakan tingkat kepentingan utiliti nilai kriteria yang besar maka untuk itu semua kriteria menggunakan persamaan rumus (3), dengan perhitungannya dapat dilihat berikut ini:

$\begin{array}{lll}\mathrm{K} 1 \max =34 & \mathrm{~K} 2 \max & =5 \\ \mathrm{~K} 1 \min =28 & \mathrm{~K} 2 \min & =2 \\ \mathrm{~K} 3 \max =5 & \mathrm{~K} 4 \max & =8 \\ \mathrm{~K} 3 \min =0 & \mathrm{~K} 4 \min & =0\end{array}$

Sehingga perhitungannya normalisasi kriteria adalah: Perhitungan beberap contoh untuk K1 dengan menggunakan persamaan rumus (3):

$$
\begin{array}{ll}
U k \mathrm{~K} 1 \mathrm{MI} & =100 * \frac{29-28}{34-28}=17 \\
U k \mathrm{~K} 1 \mathrm{AZ} & =100 * \frac{31-28}{34-28}=50 \\
U k \mathrm{~K} 1 \mathrm{LO} & =100 * \frac{28-28}{34-28}=0 \\
U k \mathrm{~K} 1 \mathrm{ABD} & =100 * \frac{29-28}{a 4-28}=17 \\
\text { Perhitungan } & \text { beberapa } \\
\text { menggunakan persamaan rumus }(3): \\
U k \mathrm{~K} 2 \mathrm{MI} & =100 * \frac{4-2}{5-2}=67 \\
U k \mathrm{~K} 2 \text { AZ } & =100 * \frac{5-2}{5-2}=100 \\
U k \mathrm{~K} 2 \text { LO } & =100 * \frac{2-2}{5-2}=0 \\
U k \mathrm{~K} 2 \text { ABD } & =100 * \frac{2-2}{5-2}=0
\end{array}
$$$$
\text { Perhitungan beberapa contoh untuk K2 dengan }
$$

Sehingga hasil perhitungan normalisasi kriteria dapat dilihat pada Tabel 5. 
Tabel 5. Normalisasi Kriteria

\begin{tabular}{cccccc}
\hline No & Alternatif & K1 & K2 & K3 & K4 \\
\hline 1 & MI & 17 & 67 & 100 & 100 \\
2 & AZ & 50 & 100 & 80 & 50 \\
3 & LO & 0 & 0 & 0 & 0 \\
4 & ABD & 17 & 0 & 60 & 50 \\
5 & YH & 100 & 67 & 20 & 50 \\
6 & DA & 67 & 33 & 20 & 38 \\
7 & HS & 100 & 0 & 40 & 25 \\
8 & AB & 50 & 33 & 20 & 13 \\
9 & MA & 0 & 67 & 20 & 13 \\
\hline
\end{tabular}

Sumber: Hasil Penelitian (2020)

d. Menentukan nilai akhir dengan menggunakan persamaan rumus (4) perhitungannya sebagai berikut:

\begin{tabular}{|c|c|c|}
\hline Nta MI K1 & $=17 * 0.1$ & $=2$ \\
\hline Nta MI K2 & $=67 * 0.2$ & $=1$ \\
\hline Nta MI K3 & $=100 * 0.3$ & $=3$ \\
\hline Nta MI K4 & $=100 * 0.4$ & $=4$ \\
\hline
\end{tabular}

Sehingga perhitungan nilai akhir dari analisa metode SMART dapat dilihat pada Tabel 6.

Tabel 6. Hasil Nilai Akhir

\begin{tabular}{ccccccc}
\hline No & Alt & K1 & K2 & K3 & K4 & $\begin{array}{c}\text { Nilai } \\
\text { Akhir }\end{array}$ \\
\hline 1 & MI & 2 & 13 & 30 & 40 & 85 \\
2 & AZ & 5 & 20 & 24 & 20 & 69 \\
3 & LO & 0 & 0 & 0 & 0 & 0 \\
4 & ABD & 2 & 0 & 18 & 20 & 40 \\
5 & YH & 10 & 13 & 6 & 20 & 49 \\
6 & DA & 7 & 7 & 6 & 15 & 34 \\
7 & HS & 10 & 0 & 12 & 10 & 32 \\
8 & AB & 5 & 7 & 6 & 5 & 23 \\
9 & MA & 0 & 13 & 6 & 5 & 24 \\
\hline
\end{tabular}

Sumber: Hasil Penelitian (2020)

Dari Tabel 6 dari 9 alternatif yang ada didapatkan hasil akhir yang telah analisa dengan menggunakan metode SMART. Alternatif yang terbaik adalah nilai akhir yang tertinggi berada pada nomor 1 yaitu MI dengan hasil akhir 85, sehingga MI di tetapkan sebagai dosen terbaik hasil analisa menggunakan metode SMART.

e. Hasil Perbandingan Pengujian

Hasil akhir pada Tabel 6 diurutkan dari nilai tertinggi ke nilai terendah dan dirangking dari rangking 1 dan seterusnya, hasil perangkingan dibandingkan dengan data dosen berprestasi SMB 2019 dapat dilihat pada Tabel 7.
Tabel 7. Hasil Perbandingan

\begin{tabular}{cccccc}
\hline No & $\begin{array}{c}\text { Metode } \\
\text { SMART }\end{array}$ & Rangking & $\begin{array}{c}\text { Data } \\
\text { SMB }\end{array}$ & Rangking & Ket \\
\hline 1 & MI & 1 & MI & 1 & PS \\
2 & AZ & 2 & AZ & 2 & PS \\
3 & YH & 3 & YH & 3 & PS \\
4 & ABD & 4 & ABD & 4 & PS \\
5 & DA & 5 & DA & 5 & PS \\
6 & HS & 6 & HS & 6 & PS \\
7 & MA & 7 & AB & 7 & PTS \\
8 & AB & 8 & MA & 8 & PTS \\
9 & LO & 9 & LO & 9 & PS \\
\hline
\end{tabular}

Sumber: Hasil Penelitian (2020)

Pada Tabel 7 terdapat 2 orang dosen yang hasilnya peringkatnya tidak sama, karena peringkatnya tidak sesuai dengan data dosen berprestasi SMB tahun 2019.

Pada Tabel 7 kolom keterangan terdapat singkatan PS artinya perbandingan sama dan PTS artinya perbandingan tidak sama.

\section{Kesimpulan}

Berdasarkan hasil perbandingan total alternatif yang sama di bagi dengan total keseluruhan alternatif maka tingkat akurasi sangat tinggi yaitu $79 \%$ sehingga penelitian ini menghasilkan kriteria yang sangat tepat. Sehingga penelitian ini menjadi indikator dalam penentuan dosen berprestasi.

\section{Daftar Rujukan}

[1] Fiqih, M., \& Kusnadi, Y. (2017). Sistem Pendukung Keputusan Pemilihan Dosen Berprestasi Dengan Metode Simple Additive Weighting. Information System For Educators And Professionals, 20(2), 41-50.

[2] Purnamasari, I., \& Afnisari, K. (2018). Performansi Klasifikasi Dosen Berprestasi Menggunakan Metode Naive Bayes Classifier. Jurnal Komputer dan Informatika Akademik Bina Saran Informatika, 20(2), 45-50.

[3] Sundar, S., Wanto, A.., Saifullah \& Gunawan, I. (2017). Sistem Pendukung Keputusan Dengan Menggunakan Metode Electre Dalam Merekomendasikan Dosen Berprestasi Bidang Ilmu Komputer (Study Kasus di AMIK \& STIKOM Tunas Bangsa). Seminar Nasional Multi Disiplin Ilmu, 1-6.

[4] Aldo, D., Putra, N., \& Munir, Z. (2019). Sistem Pendukung Keputusan Penilaian Kinerja Dosen Dengan Menggunakan Metode Multi Attribute Utility Theory (Maut). Jurnal Sistem Informasi dan Manajemen, 7(2), 16-22.

[5] Na'am, J. (2017). Sebuah Tinjauan Penggunaan Metode Analythic Hierarchy Process (AHP) dalam Sistem Penunjang Keputusan (SPK) pada Jurnal Berbahasa Indonesia. Jurnal Media Sisfo, Hal. 888-895. 
[6] Djasmayena, S., Yunus, Y., \& Putra, R, E. (2017). Pemilihan Supplier Obat yang Tepat Menggunakan Metode Multi Attribut Utility Theory. 1(4). 47-54.

DOI: https://doi.org/10.37034/jidt.v1i4.27

[7] Nofriansyah, D,. \& Sarjon, D. (2017). Multi Ariteria Decision Making (MCDM pada sistem pendukung keputusan. Publish: Group Penerbitan DC. Budi Utama).

[8] Kustiyahningsih, Y., \& Syafa'ah, N. (2015). Sistem Pendukung Keputusan Untuk Menentukan Jurusan Pada Siswa SMA Menggunakan Metode KNN dan SMART. Jurnal Sistem Informasi Indonesia. 1(1).

[9] Yulianti, E. (2015). Sistem Pendukung Keputusan Pemilihan Mobil Dengan Metode Simple Multy Attribute Rating (SMART). Jurnal Momentum. $7(1)$.

[10] Goodwin, P., \& Wright, G. (2009). Decision Analysis For Management Judgment $4^{\text {nd }}$ Edition. Publish: Wiley. 